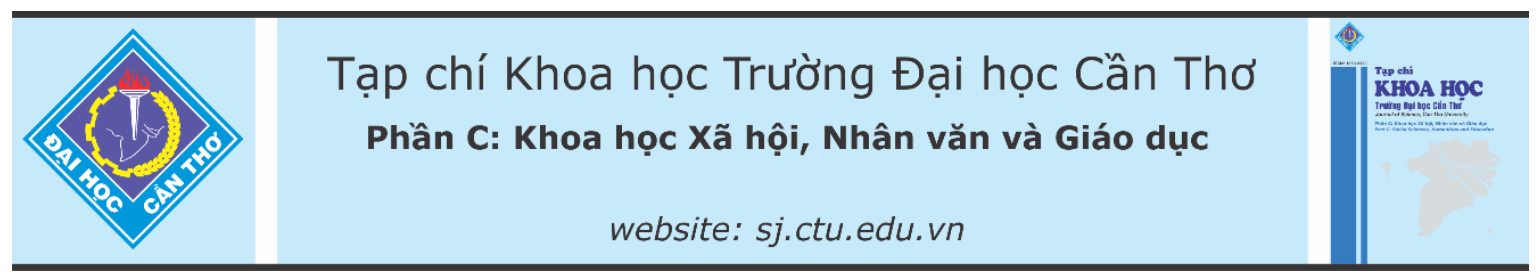

DOI:10.22144/ctu.jvn.2021.027

\title{
CÁC YẾU TỐ ẢNH HƯởNG ĐẾN SINH KẾ CỦA CỦ DÂN VÙNG HẠN MặN Ở ĐỒNG BẰNG SÔNG CỦU LONG
}

\author{
Nguyễn Tiến Dũng* và Phan Thuận \\ Hoc viện Chính trị khu vục IV \\ *Người chịu trách nhiệm về bài viết: Nguyễn Tiến Dũng (email: nguyentiendung24071959@gmail.com)
}

\section{Thông tin chung:}

Ngày nhận bài: 04/10/2020

Ngày nhận bài sứa: $23 / 12 / 2020$

Ngày duyệt đăng: 27/02/2021

Title:

Factors affecting local residents' livelihood in the drought and saltwater intrusion in the Mekong Delta

\section{Tù khóa:}

Các yếu tố, hạn mặn, kết quả sinh kế, sinh kế thu nhập

\section{Keywords:}

Factors, drought and salinity, livelihood outcome, livelihood, income

\begin{abstract}
The study is aimed to identify the factors influencing residents' livelihood in the drought and saltwater intrusion in the Mekong Delta. Data were collected from the survey of 300 randomly selected farmers in Soc Trang, Kien Giang and Tra Vinh provinces. With random sampling method, each province was selected two districts, and each district was selected one commune. Multiple regression model was used to analyze the factors affecting the livelihood outcome. The resultse show that income is one of the factors of livelihood outcome, and there are many factors affecting income of residents in salty drought area. Credit has negative correlation with the livelihood output while total farmland area, experiences, support of local goverments, sources of income, means of production had positive correlation with the livelihood outcome. On the basis of this, a number of solutions has been proposed to help the residents adapt to drought and saltwater intrusion in the coming year at the research sites.
\end{abstract}

\section{TÓM TẮT}

Mư đích của bài viết là nhận diện các yếu tố ảnh huởng đến kết quả sinh kế của cu dân vùng hạn mặn ở đồng bằng sông Củu Long. Số liệu của nghiên cứu được thu thập tù̀ 300 nông hộ ở Sóc Trăng, Kiên Giang và Trà Vinh với phuơng pháp chọ mẫu ngẫu nhiên, mỗi tỉnh lự chọn 02 huyện và mỗi huyện lự chọn 01 xã. Phuơng pháp phân tích hồi quy đa biến được dùng trong nghiên cưu này nhằm xem xét các yếu tố ảnh huởng đến kết quả sinh kế của cu dân vùng hạn mặn. Kết quả nghiên cứu cho thấy, thu nhập là một trong nhũng yểu tố của kết quả sinh kế và có nhiều yếu tố ảnh hương đến thu nhập của cu dân vùng hạn mặn. Vốn vay có mối quan hệ ngược chiều, trong khi đó đất sản xuất nông nghiệp, số nguồn thu nhập, kinh nghiệm, hỗ trọ của địa phương, số phưong tiện sản xuất có mối quan hệ cùng chiều với thu nhập. Trên co sơ đó, một số giải pháp đuợc đề xuất nhằm giúp nguời dân thich úng với hạn mặn trong thời gian tới tại địa bàn nghiên cứu. 


\section{GIỚI THIỆU}

Báo cáo đánh giá về hạn hán và xâm nhập mặn ở Đồng bằng sông Cửu Long (ĐBSCL) của Trung tâm Nghiên cứu Đông Nam Á (2016) và khảo sát tại 3 tỉnh Bến Tre, Trà Vinh và Kiên Giang cho thấy tình trạng hạn mặn ở ĐBSCL có nhiều nguyên nhân như El Niño, quản lý nguồn nước, ... Tình trạng hạn hán và xâm nhập mặn ở ĐBSCL đã diễn ra ngày càng nghiêm trọng, đặc biệt là trong năm 2016. Nghiên cứu này chỉ ra rằng hạn mặn bắt đầu từ tháng 12 , đạt đến đỉnh điểm là tháng 3,4 và sau đó giảm xuống. Trong khi đó, người dân và chính quyền địa phương chưa có nhiều ứng phó với hạn mặn trước đó. Hạn mặn này đã tác động rất lớn đến sinh kế của người dân, đặc biệt là trong sinh kế nông nghiệp (CGIAR, 2016). Bởi lẽ, hoạt động sinh kế của người dân vùng hạn mặn ven biển ở ĐBSCL rất đa dạng, song nông nghiệp vẫn là hoạt động chính (Nguyễn Duy Cần và Võ Hồng Tú, 2019).

Sinh kế bao gồm cả năng lực, tài sản (bao gồm cả nguồn lực về vật chất và xã hội) và các hoạt động thiết yếu đối với tiềm lực của cuộc sống (UNDP et al., 2015). Có thể nói, khi nói đến sinh kế hộ gia đình là nói đến ba yếu tố cấu thành, gồm các hoạt động của sinh kế, khả năng/năng lực thực hiện sinh kế hay kết quả sinh kết và tài sản sinh kế. Các nghiên cứu trước đây đã chỉ ra kết quả sinh kế chịu ảnh hưởng rất nhiều yếu tố. Trần Thị Minh Ngọc (2016) cho rằng các yếu tố ảnh hưởng đến quả sinh kế gồm nhận thức của cư dân về tầm quan trọng của các nguồn lực đối với sinh kế, các chủ trương chính sách, pháp luật, các rủi ro do thiên tai dịch bệnh. Trước đó, Nguyễn Văn Cường (2015), Võ Văn Tuấn và Lê Cảnh Dũng (2015) đã xác định các yếu tố ảnh hưởng đến sinh kế của cư dân ven biển là trình độ học vấn của lao động chính, đa dạng sinh kế, ảnh hường của tự nhiên, xã hội, đất sản xuất, ... Nguyễn Duy Cần và Võ Hồng Tú (2019) chochỉ ra mối quan hệ giữa các yếu tố ảnh hưởng với kết quả sinh kế, chẳng hạn vay vốn có mối quan hệ ngược chiều, trong khi đó kinh nghiệm sản xuất, giá trị phương tiện,... có mối quan hệ cùng chiều với kết quả sinh kế.
Có thể nói, các nghiên cứu trước đó đã chỉ ra nhiều yếu tố ảnh hưởng đến sinh kế của nông hộ. Trong bối cảnh hạn mặn, xác định được các yếu tố ảnh hưởng là một trong những nhiệm vụ quan trọng nhằm đề xuất các giải pháp góp phần cải thiện sinh kế cho cư dân ở ĐBSCL. Do đó, mục đích của bài viết này là nhận diện những yếu tố ảnh hưởng và so sánh với những phát hiện của các nghiên cứu trước đó nhằm đề xuất ra nhiều giải pháp giúp người dân ĐBSCL có thể thích ứng với hạn mặn trong thời gian tới.

\section{PHƯƠNG PHÁP NGHIÊN CÚU}

\subsection{Phương pháp thu thập thông tin}

Nghiên cứu đã tiến hành khảo sát 300 người dân ở tại Sóc Trăng, Kiên Giang và Trà Vinh để thu thập thông tin định tính và định lượng về nguồn vốn sinh kế, kết quả sinh kế và sự chuyển đổi mô hình sinh kế trong bối cảnh hạn mặn. Cuộc khảo sát diễn ra từ ngày 15 đến 25 tháng 6 năm 2020. Các hộ nông dân được lựa chọn theo hoạt động sinh kế từ các xã đã được lựa chọn (xã Vân Khánh, Vĩnh Bình Nam thuộc tỉnh Kiên Giang; xã An Lạc Tây và Trung Bình thuộc tỉnh Sóc Trăng; xã Hàm Tâm và Duyên Hải thuộc tỉnh Trà Vinh).

\subsection{Phương pháp phân tích}

Các nghiên cứu trước đây đã chỉ ra rằng thu nhập là một trong những tiêu chí đánh giá kết quả sinh kế (Nguyễn Duy Cần \& Võ Hồng Tú, 2019; Trần Thị Minh Ngọc, 2016; Võ Văn Tuấn \& Lê Cảnh Dũng, 2015). Thu nhập của cư dân vùng hạn mặn ở ĐBSCL được bằng đơn vị triệu đồng/năm/hộ. Bằng những thông tin định tính từ công cụ cây vấn đề đã giúp nghiên cứu xác định được yếu tố ảnh hưởng như: số lượng nguồn lao động chính trong hộ gia đình, đất sản xuất, kinh nghiệm sản xuất, hỗ trợ của địa phương, vay vốn,.... Đây là cơ sở để xây dựng mô hình các yếu tố ảnh hưởng đến sinh kế của cư dân vùng hạn mặn ở ĐBSCL, để từ đó có cơ sở đề xuất các giải pháp phát triển sinh kế của người dân vùng hạn mặn. Các yếu tố của mô hình này được thể hiện ở Bảng 1. 
Bảng 1. Các nhân tố ảnh hưởng đến kết quả sinh kế của cư dân vùng hạn mặn

\begin{tabular}{|c|c|c|c|}
\hline Vốn sinh kế & Biến số & Diễn giải & Nguồn \\
\hline Con người & $\begin{array}{l}\text { Số lao động chính } \\
\text { Kinh nghiệm SX }\end{array}$ & $\begin{array}{l}\text { + Đo bằng số lượng người } \\
\text { + Đo bằng số năm }\end{array}$ & $\begin{array}{l}\text { Nguyễn Duy Cần và Võ Hồng } \\
\text { Tú (2019); Võ Văn Tuấn và } \\
\text { Lê Cảnh Dũng (2015) }\end{array}$ \\
\hline Xã hội & Hỗ trợ của & $\begin{array}{l}\text { Đo bằng thang đo định danh: } \\
\text { 1: có, } 0: \text { không }\end{array}$ & $\begin{array}{l}\text { Tổng hợp từ nghiên cứu định } \\
\text { tính }\end{array}$ \\
\hline Tài chính & $\begin{array}{l}\text { Vay vốn } \\
\text { Nguồn thu nhập }\end{array}$ & $\begin{array}{l}\text { + Đo bằng thang đo định } \\
\text { danh: } 1 \text { : có, } 0: \text { không } \\
\text { + Đo bằng số nguồn thu }\end{array}$ & $\begin{array}{l}\text { Nguyễn Duy Cần và Võ Hồng } \\
\text { Tú (2019); Võ Văn Tuấn và } \\
\text { Lê Cảnh Dũng (2015) }\end{array}$ \\
\hline Tự nhiên & Đất sản xuất & $\begin{array}{l}\text { + Đo bằng tổng số diện tích } \\
\text { (cả có và thuê) }\left(1000 \mathrm{~m}^{2}\right)\end{array}$ & $\begin{array}{l}\text { Nguyễn Duy Cần và Võ Hồng } \\
\text { Tú (2019); Võ Văn Tuấn và } \\
\text { Lê Cảnh Dũng (2015) }\end{array}$ \\
\hline Vật chất & $\begin{array}{l}\text { Số lượng phương tiện } \\
\text { vật chất phục vụ sản } \\
\text { xuất của nông hộ }\end{array}$ & $\begin{array}{l}\text { + Đo bằng số lượng phương } \\
\text { tiện }\end{array}$ & $\begin{array}{l}\text { Tổng hợp từ nghiên cứu định } \\
\text { tính }\end{array}$ \\
\hline
\end{tabular}

(Nguồn: Tác giả tổng hợp, 2020)

\section{KÊTT QUẢ NGHIÊN CÚU}

\subsection{Kết quả hoạt động sinh kế của cư dân vùng hạn mặn}

Kết quả khảo sát tại các địa phương cho thấy thu nhập trung bình của nông hộ ở Sóc Trăng là cao nhất (142,89 triệu đồng/năm), tiếp đến là Kiên Giang với 66,23 triệu đồng/năm và thấp nhất là Trà Vinh với 60,58 triệu đồng/năm. Trong đó, thu nhập bình quân của hộ gia đình có sinh kế nuôi trồng thủy sản là cao hơn thu nhập bình quân của hộ có sinh kế canh tác nông nghiệp các địa phương; ngoại trừ tỉnh Kiên
Giang. Ngoài ra, sinh kế hoạt động phi nông nghiệp tương đối khá, cao hơn cả sinh kế nông nghiệp và nuôi trồng, đánh bắt thủy sản ở các địa phương, cao nhất là tỉnh Sóc Trăng và thấp nhất là Trà Vinh. Nguyên nhân có sự khác biệt này là do tỷ lệ người dân có sinh kế trong hoạt động phi nông nghiệp của tỉnh Trà Vinh làm những nghề tự do (làm thuê, tài xế, công nhân,...) chiếm $16,8 \%$ so với $2 \%$ của tỉnh Kiên Giang và $0 \%$ của tỉnh Sóc Trăng. Trong khi đó, có $17 \%$ cư dân ở Sóc Trăng có sinh kế phi nông nghiệp là buôn bán kinh doanh so với $6 \%$ của cư dân ở Trà Vinh.

\section{Bảng 2. Thu nhập bình quân của nông hộ (triệu đồng/năm)}

\begin{tabular}{llrrr}
\hline Tỉnh & \multicolumn{1}{c}{ Hoạt động sản xuất chính } & N & Trung bònh & Độ lệch chuẩn \\
\hline \multirow{4}{*}{ Sóc Trăng } & Canh tác nông nghiệp & 67 & 133,46 & 43,47 \\
& Nuôi trồng và đánh bắt thủy sản & 17 & 151,47 & 45,24 \\
& Phi nông nghiệp & 16 & 173,25 & 52,39 \\
\cline { 2 - 5 } & Tổng & 100 & 142,89 & 47,21 \\
\hline \multirow{4}{*}{ Kiên Giang } & Canh tác nông nghiệp & 14 & 93,07 & 72,80 \\
& Nuôi trồng và đánh bắt thủy sản & 79 & 57,50 & 41,04 \\
& Phi nông nghiệp & 7 & 111,00 & 39,91 \\
\cline { 2 - 5 } & Tổng & 100 & 66,23 & 49,23 \\
\hline \multirow{3}{*}{ Trà Vinh } & Canh tác nông nghiệp & 35 & 58,05 & 24,78 \\
& Nuôi trồng và đánh bắt thủy sản & 41 & 65,53 & 32,69 \\
& Phi nông nghiệp & 24 & 55,79 & 20,87 \\
\cline { 2 - 5 } & Tồng & 100 & 60,58 & 27,60 \\
\hline
\end{tabular}

(Nguồn: Số liệu khảo sát, 2020, n=300)

Như vậy, thu nhập trung bình của cư dân có sinh kế phi nông nghiệp cao nhất, tiếp đến là sinh kế nuôi trồng thủy sản và thấp nhất là sinh kế canh tác nông nghiệp. Điều này cho thấy hoạt động canh tác nông nghiệp chưa mang lại thu nhập cho cư dân ở vùng hạn mặn ở ĐBSCL. Do đó, trong bối cảnh hạn mặn như hiện nay, chuyển đổi hoạt động sinh kế canh tác nông nghiệp sang các hoạt động sinh kế khác là cần thiết.

Về tình trạng phân hóa thu nhập, thu nhập được phân chia theo ngũ phân và kết quả khảo sát cho thấy nhóm có thu nhập nhất (nhóm 1) thì có tới 27,0\% 
cư dân có sinh kế trong hoạt động nuôi trồng thủy sản so với lần lượt $12,8 \%$ và $8,6 \%$ của cư dân có sinh kế trong canh tác nông nghiệp và phi nông nghiệp; trong khi đó nhóm có thu nhập cao nhất (nhóm 5) thì chỉ có 10,3\% cư dân có sinh kế trong hoạt động nuôi trồng và đánh bắt thủy sản so với $23,3 \%$ cư dân có sinh kế trong hoạt động nông nghiệp và $27,7 \%$ của cư dân có sinh kế trong hoạt động phi nông nghiệp.

Ngoài ra, nghiên cứu còn phân tích sự chênh lệch thu nhập giữa nhóm có thu nhập thấp và cao nhất của cư dân trong các hoạt động sinh kế. Kết quả khảo sát cho thấy, chênh lệch này của hoạt động sinh kế nuôi trồng và đánh bắt thủy sản là 6,2 lần, phi nông nghiệp là 5,5 lần và hoạt động canh tác nông nghiệp là 5,0 lần. Điều này có thể giải thích rằng thu nhập của hoạt động nuôi trồng và đánh bắt thủy sản có cao hơn so với hoạt động nông nghiệp nhưng rủi ro cũng rất cao. Thực tế cho thấy có nhiều hộ gia đình làm giàu nhờ hoạt động này nhưng cũng không ít hộ gia đình trắng tay sau những lần rủi ro.

\subsection{Mô hình các yếu tố ảnh hưởng đến kết quả sinh kế của cư dân vùng hạn mặn ở ĐBSCL}

Nguyễn Duy Cần và Võ Hồng Tú (2019) đã phân tích mô hình hồi quy về các yếu tố ảnh hưởng đến kết quả sinh kế của cư dân vùng hạn mặn ở Kiên Giang và Sóc Trăng cho thấy giá trị phương tiện, diện tích đất sản xuất có tác động cùng chiều với thu nhập; trong khi đó các biến số về vay vốn, kinh nghiệm sản xuất có tác động ngược chiều. Nghiên cứu này cho thấy có một vài biến số có tác động tương tự như Nguyễn Duy Cần và Võ Hồng Tú (2019), song cũng có sự khác biệt. Kết quả từ mô hình hồi quy trong nghiên cứu này, 7 biến số độc lập được xác định như trong Bảng 3 với hệ số $\mathrm{R}^{2}=$ 0,299 , tức là các yếu tố trong mô hình có ảnh hưởng đến sự biến động về kết quả sinh kế của cư dân vùng hạn mặn chiếm $29,9 \%$, còn $70,1 \%$ do các yếu tố không xem xét trong mô hình. Sở dĩ giá trị $\mathrm{R}^{2}$ hiệu chỉnh chưa tới $50 \%$ là có thể do nhiều lý do như số lượng mẫu chưa đủ lớn và các dạng dữ liệu chưa thống nhất. Hệ số Beta cho biết cường độ ảnh hưởng của các yếu tố ảnh hưởng đến kết quả sinh kế. Hệ số VIF của các biến số độc lập đều nhỏ hơn 10 cho nên không có đa cộng tuyến xảy ra.

Bảng 3. Mô hình hồi quy về các yếu tố ảnh hưởng đến kết quả sinh kế

\begin{tabular}{lrrrr}
\hline Biến số & Hệ số B & Hệ số Beta & Sig & VIF \\
\hline Hằng số & 32,660 & & 0,026 & \\
Số phương tiện phục vụ SX & $24,977^{* * * *}$ & 0,207 & 0,000 & 3.053 \\
Kinh nghiệm trong sản xuất & $1,193^{* *}$ & 0,123 & 0,025 & 1.089 \\
Số lượng nguồn thu & $33,060^{* * *}$ & 0,287 & 0,000 & 1.002 \\
Số lao động chính & $11,096^{* *}$ & 0,165 & 0,006 & 2.034 \\
Có hỗ trợ của địa phương & $10,064^{*}$ & 0,189 & 0,035 & 4.039 \\
Có vay vốn & $-10,890^{* *}$ & $-0,091$ & 0,007 & 2.702 \\
Tổng diện tích đất sản xuất & $5,078^{* * *}$ & 0,228 & 0,000 & 1.004 \\
\hline $\mathrm{R}^{2}=0,299$ & & & & \\
$\mathrm{~N}=293$ & & & & \\
\hline
\end{tabular}

(Nguồn: Kết quả khảo sát, $2020(n=300))$

*Ghi chú: ***, **, *: Mức ý nghĩa lần luợt là 1\%; 5\% và 10\%;

Kết quả của mô hình về các yếu tố ảnh hưởng đến kết quả sinh kế của cư dân vùng hạn mặn cho thấy số lượng phương tiện phục vụ sản xuất trong hộ gia đình có mối quan hệ cùng chiều với thu nhập. Nếu ước tính hộ gia đình có tăng thêm số phương tiện phục vụ cho sản xuất thì thu nhập của hộ có khả năng tăng lên khoảng 24,9 triệu đồng/năm, mức độ ảnh hưởng của biến số này đối với thu nhập chiếm 20,7\%. Để kiểm chứng cho kết luận này, nghiên cứu đã tiến hành phân tích mối tương quan giữa số lượng phương tiện và thu nhập với giá trị kiểm định có ý nghĩa thống kế dưới 0,005 (sig=0,000) cho thấy chỉ có $16,3 \%$ nhóm cư dân có 01 phương tiện sản xuất nằm trong nhóm $20 \%$ thu nhập cao nhất so với $23,1 \%$ nhóm dân cư có $2-3$ phương tiện sản xuất. Ngược lại, có tới $21,7 \%$ nhóm $20 \%$ thu nhập thấp nhất có 01 phương tiện sản xuất so với $5,1 \%$ của người dân cùng nhóm thu nhập có 2-3 phương tiện sản xuất (Bảng 4). 
Bảng 4. Tương quan giữa số lượng phương tiện với nhóm thu nhập (\%)

\begin{tabular}{lrrr}
\hline \hline & $\begin{array}{r}\text { Có 1 phương tiện } \\
\text { sản xuất }\end{array}$ & $\begin{array}{r}\text { Có từ 2-3 phương tiện sản } \\
\text { xuất }\end{array}$ & Chung \\
\hline Nhóm 1 (thấp nhất) & 21,7 & 5,1 & 17,4 \\
Nhóm 2 & 27,1 & 12,8 & 23,4 \\
Nhóm 3 & 15,8 & 33,3 & 20,4 \\
Nhóm 4 & 19,0 & 25,6 & 20,7 \\
Nhóm 5 (cao nhất) & 16,3 & 23,1 & 18,1 \\
\hline Tổng & 100 & 100 & 100 \\
\hline
\end{tabular}

(Nguồn: Số liệu khảo sát, 2020, n=300)

Đối với biến số về kinh nghiệm sản xuất, Bảng 3 cho thấy kinh nghiệm sản xuất có mối quan hệ cùng chiều với thu nhập của hộ gia đình. Nếu ước tính tăng thêm 1 năm kinh nghiệm sản xuất thì thu nhập của hộ gia đình tăng khoảng 1,2 triệu đồng/năm, mức độ ảnh hưởng của biến số này đối với thu nhập của hộ gia đình chỉ chiếm khoảng $12,3 \%$. Điều này được khẳng định nhóm $20 \%$ thu nhập từ khá trở lên đều có kinh nghiệm sản xuất trên 10 năm trong khi đó nhóm $20 \%$ thu nhập từ trung bình trở xuống có kinh nghiệm sản xuất dưới 10 năm (Bảng 5) (với mức ý nghĩa thống kê sig. $=0,004<0,005$ ). Điều này được giải thích rằng khi người dân có kinh nghiệm trong sản xuất thì họ có thể chủ động thích ứng với hạn mặn và thông qua những thất bại trước đó, họ có thể rút ra kinh nghiệm sản xuất tốt hơn.

Bảng 5. Tương quan giữa kinh nghiệm sản xuất với nhóm thu nhập (\%)

\begin{tabular}{lrrr}
\hline & Dưới 10 năm & Tù̀ 10 trở lên & Chung \\
\hline Nhóm 1 (thấp nhất) & 16,2 & 12,4 & 14,2 \\
Nhóm 2 & 23,9 & 22,2 & 23,0 \\
Nhóm 3 & 29,6 & 19,0 & 24,2 \\
Nhóm 4 & 14,8 & 26,8 & 21,0 \\
Nhóm 5 (cao nhất) & 15,5 & 19,6 & 17,6 \\
\hline Tống & 100 & 100 & 100 \\
\hline
\end{tabular}

(Nguồn: Số liệu khảo sát, 2020, n=300; mưc ý nghĩa thống kê sig =0,004)

Đối với nguồn thu nhập, Bảng 3 cho thấy số nguồn thu nhập có cũng có mối quan hệ cùng chiều với thu nhập của hộ gia đình. Ước tính nếu tăng thêm 1 nguồn thu thì thu nhập của hộ gia đình sẽ tăng thêm khoảng 33 triệu đồng/năm, mức độ tác động của biến số này với thu nhập là $28,7 \%$, có cường độ tác động cao nhất so với các biến số khác.

\section{Bảng 6. Tương quan giữa số lượng nguồn thu với nhóm thu nhập (\%)}

\begin{tabular}{lrrr}
\hline & Có 01 nguồn thu & Có 02 nguồn thu & Chung \\
\hline Nhóm 1 (thấp nhất) & 24,9 & 4,8 & 17,8 \\
Nhóm 2 & 28,5 & 14,3 & 23,5 \\
Nhóm 3 & 22,3 & 16,2 & 20,1 \\
Nhóm 4 & 11,9 & 37,1 & 20,8 \\
Nhóm 5 (cao nhất) & 12,4 & 27,6 & 17,8 \\
\hline Tống & 100 & 100 & 100 \\
\hline
\end{tabular}

(Nguồn: Số liệu khảo sát, 2020, n=300; mưc ý nghĩa thống kê sig =0,007)

Điều này được củng cố thông qua mối tương quan giữa nhóm thu nhập và nguồn thu cho thấy, nhóm cư dân thuộc nhóm $20 \%$ thu nhập thấp nhất chỉ có 1 nguồn thu chiếm tới $24,9 \%$ so với $4,8 \%$ người dân cùng thu nhập nhưng có 2 nguồn thu; trong khi đó, có tới $27,6 \%$ nhóm $20 \%$ thu nhập cao nhất có 2 nguồn thu so với $12,4 \%$ cùng nhóm thu nhập có 2 nguồn thu. Cho nên, để tăng thu nhập cho người dân thì cần phải quan tâm đến đa dạng hóa nguồn thu.

Đối với biến số về hỗ trọ địa phưong, kết quả mô hình hồi quy cho thấy mối quan hệ giữa biến số hỗ trợ của địa phương với thu nhập là mối quan hệ cùng chiều, nếu có sự hỗ trợ của địa phương thì thu nhập của người dân tăng lên khoảng 10 triệu đồng/năm. Điều này cho thấy hỗ trợ của địa phương có đóng góp tích cực vào sinh kế của người dân ở vùng hạn 
mặn. Thực tế cho thấy trong những năm qua, người dân ở các địa phương đã nhận được nhiều sự hỗ trợ của chính quyền như vay vốn với lãi suất ưu đãi; tập huấn chăn nuôi, nuôi trồng thủy sản,;hỗ trợ giống lúa chịu mặn;... Đồng thời, chính quyền còn tư vấn cho người dân lên kế hoạch xuống giống phù hợp để tránh rủi ro của thiên tai, đặc biệt là hạn mặn. Chính điều này đã góp phần hạn chế rủi ro và mang lại thu nhập ổn định cho người dân.

Đối với biến số về lao động chính, kết quả mô hình hồi quy cũng cho thấy có mối quan hệ cùng chiều với thu nhập, ước tính nếu tăng thêm 1 người trong lực lượng lao động chính của gia đình thì thu nhập có khả năng tăng lên khoảng 11,1 triệu đồng/năm, mức độ tác động của biến số này chiếm 16,5\%. Mặc dù mức độ tác động không mạnh nhưng phản ánh được vai trò của lực lượng lao động chính trong gia đình. Sở dĩ có tác động không mạnh là do có thể chất lượng của lực lượng này chưa cao. Vì thế, xây dựng sinh kế bền vững cho cư dân vùng hạn mặn cần chú ý đến nguồn nhân lực trong gia đình, đặc biệt chất lượng của nguồn lực này.

Đối với biến số vay vốn, mô hình hồi quy cho thấy vay vốn có mối quan hệ nghịch với thu nhập, ước tính nếu mỗi hộ có vay vốn thì thu nhập hộ gia đình sẽ giảm xuống khoảng 10 triệu này, mức độ tác động của biến số này chỉ chiếm $9,0 \%$. Điều này được lý giải rằng người dân vay vốn thường thiếu điều kiện để đầu tư sản xuất cho nên kết quả sinh kế của họ kém hiệu quả hơn (Nguyễn Duy Cần và Võ Hồng Tú, 2019).

Đối với biến số tổng diện tích đất sản xuất (cả có và thuê), mô hình hồi quy cho thấy diện tích đất sản xuất có mối quan hệ cùng chiều với thu nhập. Ước tính cứ tăng khoảng $1000 \mathrm{~m}^{2}$ (1 công) đất sản xuất thì thu nhập của hộ gia đình tăng khoảng hơn 5,1 triệu đồng/năm, mức độ tác động của biến số này đối với thu nhập của nông hộ chiếm $22,8 \%$. Điều này cho thấy mở rộng diện tích đất sản xuất cũng góp phần làm tăng thu nhập cho hộ gia đình nhưng thu nhập tăng không nhiều.

\section{KẾT LUẬN VÀ KIẾN NGH!}

\subsection{Kết luận}

Trong thời gian qua, hạn mặn đã tác động mạnh mẽ đến sinh kế của người nông dân ở ĐBSCL. Sinh kế của cư dân vùng hạn mặn chủ yếu là những hoạt động canh tác nông nghiệp, nuôi trồng thủy sản. Các bằng chứng nghiên cứu định lượng đã cho thấy kết quả sinh kế của cư dân trong hoạt động canh tác nông nghiệp còn thấp so với các hoạt động sinh kế khác và tình trạng phân hóa thu nhập của hoạt động sinh kế trong hoạt động nuôi trồng và đánh bắt thủy sản còn khá cao. Nguyên nhân là do sinh kế trong hoạt động nuôi trồng thủy sản gặp nhiều rủi ro. Vì thế, các chương trình, hoạt động xây dựng sinh kế bền vững cho cư dân vùng hạn mặn cần chú ý đến đặc điểm của từng hoạt động sinh kế.

Về các yếu tố ảnh hưởng đến kết quả sinh kế, nghiên cứu đã cho thấy, kết quả sinh kế của cư dân vùng hạn mặn chịu ảnh hưởng của nhiều yếu tố. Đó là số phương tiện sản xuất, kinh nghiệm sản xuất, số lao động chính, số nguồn thu nhập, hỗ trợ của địa phương, vay vốn. Đa số các yếu tố có mối quan hệ cùng chiều với thu nhập của hộ gia đình, chỉ có yếu tố vay vốn có mối quan hệ trái chiều. Đây là một trong những cơ sở quan trọng để nghiên cứu gợi mở một số đề xuất các giải pháp phát triển sinh kế và thích ứng với hạn mặn cho người dân ở ĐBSCL trong thời gian tới. .

\subsection{Kiến nghị}

Trên cơ sở phân tích các yếu tố ảnh hưởng đến thu nhập của cư dân vùng hạn mặn, bài viết gợi mở một số kiến nghị như sau:

Thư nhất, cần đa dạng hóa sinh kế để cải thiện sinh kế bền vũng cho cu dân vùng hạn mặn. Để làm được điều này thì cần có hỗ trợ ngành nghề, tăng cường liên kết "bốn nhà" nhằm tăng chuỗi giá trị cho sản phẩm nông nghiệp; hỗ trợ, tư vấn người dân chuyển đổi sinh kế.

Thư hai, cải thiện vốn con người. Đó là chú trọng, nâng cao chất lượng đào tạo nghề cho người dân; tăng cơ hội tiếp cận giáo dục cho người dân, đặc biệt là người nghèo thông qua các chính sách hỗ trợ và miễn giảm học phí

Thư ba, cải thiện vốn tự nhiên. Để cải thiện vốn tự nhiên nhằm đảm bảo sinh kế bền vững cho cư dân vùng hạn mặn thì cần phải đẩy mạnh công tác quy hoạch đất sản xuất phù hợp từng hoạt động sinh kế; tiến hành xây dựng các biện pháp công trình nhằm hạn chế tình trạng xâm nhập mặn; đẩy mạnh nhiệm vụ bảo vệ nguồn nước ngọt, người dân cần có ý thức trong việc bảo vệ và sử dụng nguồn nước; biện pháp liên quan đến công trình như hồ trữ nước, lọc tách độ mặn trong nước; cần hạn chế đánh bắt theo kiểu “tiệt chủng” mà cần phải có biện pháp vừa đánh bắt vừa bảo vệ; ngoài ra, có biện pháp xử lý mạnh đối với các trường hợp này.

Thư tur, cải thiện vốn vật chất. Để làm được điều này thì cần có chính sách hỗ trợ hợp lý cho người dân, khuyến khích người dân đầu tư mua sắm, nâng cao chất lượng phương tiện sản xuất; đầu tư công 
nghệ hiện đại nhằm mang lại hiệu quả cao, nâng cao năng suất trong sản xuất và hạn chế rủi ro do thiên tai gây ra.

Thứ năm, cải thiện vốn tài chính. Để cải thiện vốn tài chính nhằm đảm bảo sinh kế bền vững cho cư dân vùng hạn mặn thì cần phải tăng cường khả năng tích lũy tài chính; đẩy mạnh các hình thức liên kết, hợp tác huy động vốn; tháo gỡ những khó khăn trong vay vốn ngân hàng, hạn chế tình trạng tín dụng đen.

Thư sáu, cải thiện vốn xã hội. Vốn xã hội được đánh giá dựa trên các mối quan hệ xã hội và sự uy tín trong nhóm xã hội, cộng đồng. Để cải thiện vốn xã hội nhằm xây dựng sinh kế bền vững cho cư dân vùng hạn mặn thì cần hỗ trợ kịp thời người dân khi gặp khó khăn; tăng cường và khắc phục các hạn chế trong liên kết hợp tác, phát triển các mô hình sản xuất theo tổ đội, nhân rộng mô hình hợp tác xã hội nông nghiệp làm ăn có hiệu quả; cần tiếp tục duy trì sự hỗ trợ và giúp nhau trong cộng đồng.

\section{TÀI LIỆU THAM KHẢO}

CGIAR. (2016). The drought and salinity intrusion in the Mekong River Delta of Viet Nam, Assessment Report.

Nguyễn Duy Cần \& Võ Hồng Tú (2019). Thực trạng và chiến lược sử dụng nguồn vốn sinh kế thích ứng với xâm nhập mặn của nông hô ven biển đồng bằng sông Cửu Long. Tạp chí Khoa học Đại học Cần Thơ, 55(6D), 109-118

Nguyễn Văn Cường (2015). Nghiên cứu cải thiện sinh kế trong hoạt động khai thác hải sản cho cư dân ven biển thành phố Hải Phòng.Luận án Tiến sĩ, Học viện Nông nghiệp Việt Nam, Hà Nội.

Trần Thị Minh Ngọc (2016). Sinh kế bền vững cho cư dân ven bờ vịnh Bắc Bộ- thực trạng và giải pháp. Báo cáo đề tài cấp bộ, Học viện Chính trị Quốc gia Hồ Chí Minh, Hà Nội.

Võ Văn Tuấn \& Lê Cảnh Dũng (2015). Các yếu tố ảnh hưởng đến kết quả sinh kế của nông hộ ở đồng bằng sông Cửu Long. Tạp chí Khoa học Đại học Cần Thơ, 38, 120-129.

UNDP, IRP \& ISDR (2015). Guidance note on recovery livelihood 